\title{
Beliefs, values and practices of families in the care of hospitalized children: subsidies for nursing
}

\author{
Crenças, valores e práticas de famílias no cuidado à criança hospitalizada: subsídios à enfermagem
}

Creencias, valores y prácticas de las familias en el cuidado de niños hospitalizados: subsidios para enfermería

\begin{tabular}{r}
\hline Dóris Helena Ribeiro Farias' \\
ORCID: 0000-0003-3864-0145 \\
Mauro Francisco Ferreira de Almeida' \\
ORCID: 0000-0001-7268-8471 \\
Giovana Calcagno Gomes' \\
ORCID: 0000-0002-2464-1537 \\
Valéria Lerch Lunardi' \\
ORCID: 0000-0002-0380-1829 \\
Maria Veraci de Oliveira Queiroz'" \\
ORCID: 0000-0002-7757-119X \\
Pâmela Kath de Oliveira Nörnberg' \\
ORCID: 0000-0002-5931-3234 \\
Luciano Garcia Lourenção' \\
ORCID: 0000-0002-1240-4702
\end{tabular}

'Universidade Federal do Rio Grande. Rio Grande, Rio Grande do Sul, Brazil.

"Universidade Estadual do Ceará. Fortaleza, Ceará, Brazil.

How to cite this article:

Farias DHR, Almeida MFF, Gomes GC, Lunardi VL, Queiroz MVO, Nörnberg PK, et al. Beliefs, values and practices of families do not care for hospitalized children: nursing subsidies. Rev Bras Enferm. 2020;73(Suppl 4):e20190553. doi: http://dx.doi.org/10.1590/0034-7167-2019-0553

Corresponding author:

Dóris Helena Ribeiro Farias E-mail: dorisenf@hotmail.com

EDITOR IN CHIEF: Dulce Barbosa ASSOCIATE EDITOR: Priscilla Broca

Submissão: 10-11-2019

Approval: 06-26-2020

\begin{abstract}
Objective: To know the beliefs, values and practices of families in the care of hospitalized children. Method: Qualitative study developed at the Pediatrics Unit of a University Hospital in southern Brazil through non-participant observation, participant observation and interview with children's family members. The methodological framework of Ethnonursing was adopted. Data were coded, classified and scrutinized to identify saturation of similar or different ideas and patterns, and recoded by making theoretical formulations and recommendations. Results: Beliefs, values and practices of families depend on cultural references and are manifested in the care with feeding, clothing and hygiene, maintenance of sleep and rest, presence, care with medication and exercise of religious belief. Conclusion: Family members care for the hospitalized child based on their cultural reference and it is important that nurses take this aspect into consideration during care practice. Cultural care aggregates knowledge and can be considered a new paradigm for nursing care that allows an affective, reflective, human, empathic relationship between nurse/child/family.
\end{abstract}

Descriptors: Hospitalized Child; Family; Childcare; Culture; Transcultural Nursing.

\section{RESUMO}

Objetivo: Conhecer as crenças, valores e práticas de famílias no cuidado à criança hospitalizada. Método: Estudo qualitativo com adoção do referencial metodológico da Etnoenfermagem, desenvolvido na Unidade de Pediatria de Hospital Universitário do sul do Brasil, mediante observação não participante, observação participante e entrevista com familiares das crianças. Os dados foram codificados, classificados e escrutinados para identificar saturação de ideias e padrões semelhantes ou diferentes; e recodificados, realizando-se formulações teóricas e recomendações. Resultados: Crenças, valores e práticas das famílias dependem dos referenciais culturais e manifestam-se no cuidado com a alimentação, vestuário e higiene, manutenção do sono e repouso, presença, cuidado com medicação e exercício da crença religiosa. Conclusão: A família cuida da criança hospitalizada com base em seu referencial cultural e a consideração deste aspecto pelo enfermeiro durante a prática assistencial é importante. $O$ cuidado cultural agrega saberes, pode ser considerado um novo paradigma para o cuidado de enfermagem e permite uma relação afetiva, reflexiva, humana, empática entre enfermeiro/criança/família.

Descritores: Criança Hospitalizada; Família; Cuidado da Criança; Cultura; Enfermagem Transcultural.

\section{RESUMEN}

Objetivo: Conocer las creencias, valores y prácticas de las familias en el cuidado de niños hospitalizados. Método: Estudio cualitativo desarrollado en la Unidad de Pediatría de un Hospital Universitario en el sur de Brasil a través de observación no participante, observación participante y entrevista con los familiares de los niños. Se adoptó el marco metodológico de la etnoenfermería. Los datos se codificaron, clasificaron y analizaron para identificar la saturación de ideas y patrones similares o diferentes, y se recodificaron mediante formulaciones teóricas y recomendaciones. Resultados: Las creencias, valores y prácticas de las familias dependen de referencias culturales y se manifiestan en el cuidado con alimentación, vestimenta e higiene, mantenimiento del sueño y el descanso, presencia, cuidado con medicamentos y ejercicio de creencias religiosas. Conclusión: La familia cuida al niño hospitalizado en función de su referencia cultural y es importante que los enfermeros tengan en cuenta este aspecto durante la práctica de cuidado. La atención cultural agrega conocimiento, puede considerarse un nuevo paradigma para la atención de enfermería y permite una relación afectiva, reflexiva, humana y empática entre enfermero/niño/familia.

Descriptores: Niño Hospitalizado; Familia; Cuidado del Niño; Cultura; Enfermería Transcultural. 


\section{INTRODUCTION}

Hospitalization itself is a disturbing situation in a child's life, affects and changes the life and routine of the whole family. In the hospital environment, children experience a new situation, go through a loss process characterized by the withdrawal of family, school, friends and their toys, and need to adapt to changes in their routine ${ }^{(1-2)}$. The hospitalized child is vulnerable to various stressors and undergoes invasive and painful procedures that bring suffering, and the possible experience of loneliness and fear of death.

At the hospital, the child starts to be cared for by both the family and the nursing team, and this cultural issue is directly involved in the care process ${ }^{(3)}$. The family provides care by reproducing the care practices performed at home, based on their beliefs, habits, resources and worldviews, which are not always compatible with the care culture of the multidisciplinary team. In this sense, the nursing professional working at the hospital needs to consider the client's culture when planning care ${ }^{(4)}$.

The Theory of Diversity and Cultural Universality of Care developed by Madeleine Leininger defines assumptions as ideas or beliefs and values clearly expressed in meanings, which support the prediction that different cultures perceive, know and practice care in different ways, despite the common points in the care of all cultures in the world(5).

From a cultural perspective, the family is a health care unit with its own views on health and illness, attitudes and forms of care. Family participation improves the quality of pediatric hospital care, because the family unit has great traditional value and considers affective bonds and responsibility to be very valuable ${ }^{(6)}$.

When sharing childcare with their family, nursing needs to know their cultural references of care to help them experience the child's hospitalization in the best possible way. Considering that family members are cultural beings, and culture influences the way families care for their members, the following question emerged: what are the beliefs, values and practices of families in the care of hospitalized children?

\section{OBJECTIVE}

To know the beliefs, values and practices of families in the care of hospitalized children.

\section{METHODS}

\section{Ethical aspects}

Prior to data collection, the study received a favorable opinion from the Research Ethics Committee of the Federal University of Rio Grande/FURG. The excerpts extracted from the observations were identified by the letters OBS. Participants were identified by the letter $\mathrm{F}$ followed by the interview number to ensure their anonymity.

\section{Type of study and theoretical-methodological framework}

Qualitative study of family caregivers of hospitalized children. The ethnonursing methodological framework was followed to obtain facts, feelings, worldviews and other types of data that reveal the real world, truths and ways of life of people, and allow the understanding of beliefs and values ${ }^{(7)}$.

The objective of ethnonursing as a research method is a broad understanding of the potential and real phenomenon of nursing, such as the meaning and expressions of human care in different and similar contexts ${ }^{(6)}$. Based on this concept, the assumption supported this study was: The family is a care unit that underpins children's life by supporting, sustaining and protecting them materially and emotionally, and caring for them according to the beliefs, values and references of care of such family.

\section{Methodological procedures}

\section{Study scenario and data source}

The study was carried out at the Pediatrics Unit of the Hospital Universitário Dr. Miguel Riet Corrêa Jr. (HU) in the city of Rio Grande, state of Rio Grande do Sul, Brazil. This is a medium-sized, referral hospital in maternal and childcare linked to the Federal University of Rio Grande/FURG. The pediatric unit of the HU has 18 beds for children aged between zero and 12 years old, who are hospitalized for clinical and surgical care. Up to two family members of both sexes aged over 18 years are allowed as companions per hospitalized child 24 hours a day.

Fifteen family caregivers of children hospitalized in the aforementioned hospital participated in the study. The following inclusion criteria were adopted for their selection: being a family member of the child, aged over 18 years and providing direct care in the hospital environment during the data collection period, December 2016 to May 2017. Family members who only visited the child were excluded.

The selection of participants was intentional and the number of participants was determined after achieving saturation, when information becomes redundant and repeated for the researcher at various times, and informants have nothing more to offer, as they have said and shared everything ${ }^{(7)}$.

\section{Data collection and organization}

The data collection period was between December 2016 and May 2017. The methodological model of ethnonursing, composed of observation, participation and reflection, and semi-structured interviews, was followed ${ }^{(6-7)}$. The researcher was involved in pediatrics during different shifts in order to get closer to the unit team and family caregivers. The data collection procedure comprised four phases of observation, an interview and four phases of data analysis, as recommended by Leininger, and contemplated specific and congruent criteria with the qualitative paradigm ${ }^{(6-7)}$.

Interviews were conducted in the child's own ward and recorded for later transcription. Before the interview, family members were instructed on the objectives of the study and signed the Informed Consent form (IC).

Initially, observation was performed with use of a script based on the beliefs, values and forms of care of these families, seeking to portray the expression of these aspects in the hospital environment. Each family member was observed throughout three morning shifts, three afternoon shifts, and three night shifts (7 pm to midnight). Their manifestations of childcare at 
the different times of the day were recorded in the field diary, totaling 765 hours of observation.

During non-participant observation without any interrelationship with the family ${ }^{(7)}$, we sought to enter the world of informants and have a broad view of the cultural context of the study location. In the second phase, the observation occurred with some participation, such as informal conversations and interaction with key informants by observing and perceiving their actions and responses. The researcher spent more time with each participant and followed the activities more closely, with more detailed observation.

In the third observation phase, after interaction was established, participation became more active and involved seeking to apprehend the informants' worldviews, feelings and experiences. It became apparent that the context of families comprises different ethnic origins, participants express their own way of living and their forms of care are based on their beliefs.

After the three observation phases, an interview script was developed with questions of identification and others that contemplated specific situations for each key informant. The semi-structured individual interview prioritized the meaning of the phenomenon under investigation based on informants' experience ${ }^{(7)}$. Family caregivers were asked about their way of caring and in the process of caring for hospitalized children, their culture (beliefs and values) was respected.

In the fourth phase of observation, reflective observations were made, rethinking the observed phenomenon and evaluating information recorded in the field diaries. During this period, informants could be sought again to discuss the results, thereby offering greater reliability to the results ${ }^{(4)}$. This phase was characterized by leaving the field and reflecting on the experiences with the informants.

\section{Data processing and analysis}

The statements obtained in the interviews were transcribed in full and, together with data from the observation, were analyzed in four steps, according to Leininger and McFarland ${ }^{(6)}$. In the first step, the collection and documentation of raw data were performed, when the researcher collects, describes, records and begins the analysis of data. In the second step, data were coded and classified according to the domain of the inquiry and the guiding question. The third step comprised the analysis of context and current patterns with scrutiny of data to discover the saturation of ideas and recurring patterns of similar or different meanings, and a recoding was performed. In the fourth step, the themes and relevant research findings were identified, and theoretical formulations and recommendations were made. Scientific rigor was maintained in all steps of data collection and analysis. The criteria of credibility, confirmability, saturation and transferability were used ${ }^{(7)}$.

In the analysis process, seven empirical categories were built: Caring for the diet; Caring for clothing and hygiene; Keeping the play; Caring for sleep and rest; Being present; Taking care of medication; and Exercising the religious belief.

Observation data were identified by the letters "OBS" in parentheses and the participating family members were identified by the letter " $F$ " followed by the interview number in order to ensure their anonymity.

\section{RESULTS}

Fifteen family members, 12 mothers and three grandparents, aged between 18 and 58 years participated in the study. Children were aged between five months and nine years, and 11 were male.

Data from the observations and interviews showed how the beliefs, values and practices of families in the care of hospitalized children depend on their cultural references and are manifested in this context, through care with the diet, clothing and hygiene, with playing, maintaining the sleep and rest, being present, taking care of medication and exercising religious belief.

\section{Caring for the diet}

As observed in the families' testimonies, children's food in the hospital environment is an important factor thus, family members make sure that they eat all meals. They are concerned that the diet is varied and rich, because they relate good nutrition as an essential condition for the child's recovery. Food is part of the cultural construction of each family, has a symbolic value and a relationship with the environment and the act of eating. It is more than just the intake of nutrients:

I am the one who feeds him. I put him on my lap and this way he eats. (F11)

I told the nutritionist that he doesn't eat many types of food. I think the food here is good, varied and nutritious, will make him stronger and help his recovery. (F1)

Food is a cultural heritage of each family, who have their own habits and food preferences, different from the food offered at the hospital both in the form of preparation and times of meals. This fact is perceived as a limitation to children's food intake that may compromise their recovery. They mentioned talking to the nutritionist about food preferences:

They try to adjust the hospital meal times to those of their children's routine, thus satisfying their tastes and also the way they like to be treated, reducing the interference of their habits at home. (OBS)

[...] they think that meal times are quite different from what they usually have at home, causing that many times, the child does not eat the food. (OBS)

The food here is very different from what he eats at home. So, I give it little by little, several times throughout the day. (F12)

I take great care of the quantities and the type of food served. She is used to eating fish, and here there isn't any. She eats little because she feels sick. So, I give it little by little. (F13)

I make sure he eats rice, meat and bread. (F3)

\section{Caring for clothing and hygiene}

Clothing and hygiene were also identified as forms of family care that concern mothers in the hospital environment and manifest cultural practices. The family caregiver usually changes the clothes and performs hygiene care of the child. Although hygiene 
is part of the therapeutic process of hospitalized children, the family recognizes it as a way of providing comfort, wellbeing and pleasure. It is a moment when the family caregiver communicates with the child, interacts and strengthens bonds of affection and complicity, as shown in the following statements.

Here, I like to bathe him at night, so he sleeps more relaxed. (F1)

Caring at the hospital means bathing, tooth brushing, combing the hair, putting on perfume. I like to do it with love and it's a moment of our own. (F9)

As noted, family care related to the hygiene of hospitalized children consists of bathing, changing clothes, oral hygiene, hair care and concern with always keeping them clean and tidy.

I am the one who bathes my son. I massage his back, I wash his little head well. (F4)

I am very concerned, especially with hygiene. I know we have contact with many diseases here, so we must prevent. (F1)

Bathing is a care performed by family members, who apprehend a hospital culture. Mothers become dexterous at protecting the puncture site, the surgical wound, catheters and drains with an impermeable material at bath time, as they are constantly reminded by the nursing staff about the need for body hygiene in the hospital. (OBS)

Giving a bath with an IV is difficult, it stays in the way, you have to be careful not to lose the vein, but you have to do it. He even helps and takes care of the IV. It's even fun. (F1)

My daughter uses the feeding probe. So, I place the bathtub on the bed to bathe her, because it is better. I protect the face to clean the teeth and the medical plasters, so they don't get wet. (F10)

However, some family caregivers resisted to bathe children when they had respiratory problems. They related the coldness to the possibility of worsening after the bath or washing the head.

In children with respiratory problems, there was a certain resistance from the mother to give them a bath, especially when washing the hair. They refer that the child can get worse and that in the family, hair is not washed daily when they are sick and, sometimes, even the shower is avoided. (OBS)

[...] If I were at home, I would have already made a foot soak to take the cold away because pneumonia comes from the cold. (F5)

I don't let him put his foot on the floor, so he doesn't get cold and it doesn't get worse. (F3)

Coldness appears as a reason for not taking a bath or resisting to take it [...] On cold days, they avoid giving a full bath, they are concerned that the child wears more clothes, doesn't get out of the warm bed or walks barefoot on the cold floor. (OBS)

\section{Keeping the play}

Family members understand playing as a cultural practice and as children's language of meaning of the world. The promotion of playing in the hospitalization space is essential. Through playing, family caregivers seek to make the hospital environment less hostile and they recognize it as a form of care.

I play, I hold him, he loves it, he is happy. I think we are in a heavy environment, so I try to pass the time and distract him. (F5)

I take her to the recreation. There, she plays with other children, has a little fun. I'm glad she can play. (F15)

\section{Caring for sleep and rest}

The hospital environment does not provide adequate conditions for the child's sleep and rest. The environment is organized according to the activities developed by professionals working in the department, so the child's sleep can be interrupted at any time.

I take care that at least during the night, she sleeps well. (F14)

He sleeps very late but wakes up early and no longer sleeps during the day. (F4)

When she is sleeping, I use the time to rest. I leave the room well ventilated, turn off the light and watch her sleep. (F7)

Furthermore, each child has an own sleep and rest habit according to the lifestyle. Family caregivers seek to preserve these by leaving the ward silent and bringing pillows and blankets from home with the aim to favor the child's rest.

l asked the mother of another boy to take his son to play outside the room, so mine could sleep. That little boy is very agitated, cries a lot and it is disturbing. (F3)

My daughter is finding it hard to get used to the bed. I brought her blankets and pillow from home, but she still hasn't got used to it. (F5)

Isleep with him in bed, because athomewesleep in the sameroom.(F11)

\section{Being present}

The family recognize that the child is needy and requires emotional-related care in the hospital, so they strive to be present at all moments, monitor the entire evolution of treatment and provide security for the child throughout the hospitalization experience.

I don't leave his side, looking and touching. (F1)

I accompany everything, I don't leave him alone. He has to know I'm here with him. (F9)

The difference is that I'm here with him in the afternoon and if I it were home, he would be at school. As I am here at the hospital, I can be closer to him, so he feels safe, less fearful. (F4)

Families value their presence with the child as a way of alleviating the suffering. They exercise not only physical presence, but an attentive, loving and responsible presence. By being present, family show their legitimacy as the child's caregiver in the hospital and reinforce their maternal cultural identity. 
The family presence materializes in the care readiness; in caring all day long; in meeting the request of the health team regarding child care; accompanying the child during examinations and procedures; by imposing some limits; leaving the house and the care of other children with others, so they are able to be with this child in the hospital.

Caring is spontaneous, it's mother's love. Caring like this, fully, makes me feel fulfilled. I always think something is missing. It's natural to want to take care and have pleasure in taking care of children, so they know we are a family. (F11)

I participate in everything. During procedures, I stay together, take her hand. (F15)

I prefer to be together during procedures, because my presence is important. (F14)

I abandoned everything to be here. He's our priority. We try to be as present as possible. (F12)

In addition, the family presence is a source of affection that can alleviate the child's discomfort caused by hospitalization and reinforce the affective and emotional aspects of childcare.

I give affection, because affection is the best medicine and what I can offer the most. (F13)

Attention and affection are doubled. I live with him on my lap, I kiss, touch. (F11)

We stay with him on our lap, so we do not to let him cry. (F12)

\section{Taking care of medication}

Cultural care is preserved in the hospital when family members negotiate care related to the use of medication through the supervision of its administration by nursing professionals.

It was observed that they try to control the schedule of medication, so it's not given together with food. Culturally, it was noticed that for mothers, food and medication do not go well together. (OBS)

They give medication at night and he doesn't wake up and this is very good, and if necessary, I take care of medication. (F1)

At home, I use tea when he feels something, a stomachache. But here, they only use medicine. (F2)

As most medications are administered intravenously or intramuscularly, family members are concerned with minimizing the child's pain during punctures and medication therapy.

I take care of the medication. His medication is controlled and if he receives the wrong dose, he may even die. He depends on medication to get well, so we can go home. (F15)

It is very difficult to see my son being punctured. It hurts us to see it. I try to stay together during the venipuncture. I go into the small room to help. (F12)

\section{Exercising the religious belief}

There was a strong relationship between religiosity and health and healing processes. Family caregivers resort to religion when faced with the illness, with the objective to mitigate its meaning and give it a more positive sense. Religious practice complements medical practices and presents itself as a cultural manifestation.

Religious beliefs appear as support, give them hope and encouragement in the child's recovery. Mothers often bring sculptures of saints or even pictures on paper form, scapulars, protective amulets, and pray with the child for the guardian angel and to ward off the evil eye. They believe that, in addition to the disease, children have weaknesses they cannot explain properly that require spiritual protection. (OBS)

I believe in God a lot. In my life in the first place, because He made me calm the day we received my son's diagnosis. (F8)

I continue to pray daily so that God heals her. (F6)

\section{DISCUSSION}

The perception of the family as a care unit means considering the child's psychosocial needs in different cultures, establishing trust and knowing the social context of the child's life beyond the health care environment ${ }^{(8-9)}$.

Regarding the beliefs, values and practices of families in the care of children in the hospital setting, a dependence on their cultural references was observed. In this context, such references are manifested by the care with food, clothing and hygiene, the playing, maintaining sleep and rest, being present, reproducing the home environment and the care provided at home in the hospital, the care with medication, the construction of a care support network and exercise of religious belief.

Families attribute great importance to children's food in the hospital environment. At home, children are used to a certain type of food and to have their wishes and desires often satisfied by those who care for them. This does not happen in the hospital setting, although they maintain their tastes and preferences and often refuse to eat the food offered in the hospital, which causes inconvenience ${ }^{(10)}$. Promoting new eating practices by changing habits cannot happen by imposing new knowledge, because this can change previous beliefs and generate distrust and insecurity. Nursing must provide guidance, exchange information with the family and direct it to the child too, in order to facilitate their understanding and promote the transition related to food care. During this confrontation process, it is essential to consider the characteristics and needs of each family, offer sensitive listening, as well as respect for their life history and worldview in the concrete reality of family members and the child(4).

The times and characteristics of meals influence the acceptance of food by children in the hospital setting. The aim of a study was to assess the nutritional profile of children admitted to a hospital and analyze the variables influencing nutritional diagnosis and food consumption during hospitalization. The relevance of identifying the causes impacting on nutritional status and the acceptance of food offered in the hospital environment for hospitalized children was highlighted ${ }^{(11)}$. 
Another study on strategies used by family caregivers in the care of children in the hospital showed they search for information about the food provided. The family want to know what the child can and cannot eat, meal times in the hospital and about the quantities provided in order to avoid the provision of inappropriate food and the worsening of children's status ${ }^{(12)}$.

Regarding the care of children's clothing and hygiene in the hospital, it was observed that hygiene is a strategy for promoting comfort, wellbeing and pleasure ${ }^{(13)}$. Family care related to children's hygiene in the hospital consists of bathing, changing their diapers and clothes when dirty; oral hygiene; care for the hair and concern with always keeping the child clean and tidy. Culturally, these care activities are responsibility of family members. The performance of these acts by the family caregiver is already institutionalized in pediatric inpatient units and a routine accepted by all in an uncritical and natural way. Many actions previously performed by nursing, are now seen by professionals as the family's competence ${ }^{(14)}$.

Bathing is one of the care activities performed by family members, who learn a hospital culture and become skillful at protecting the puncture site, surgical wound, catheters and drains with an impermeable material during the bath. They are constantly reminded by the nursing team about the need for body hygiene in the hospital to prevent nosocomial infections and avoid disturbing the wound healing process ${ }^{(13)}$.

The uniqueness of childhood must be considered, and the activity of playing is a way of maintaining and providing children's right to express, live and elaborate the experience of illness and hospitalization. Playing is a cultural practice and the language of meaning of the world by the child. Its promotion in the hospitalization environment of children is fundamental. The hospital setting is unknown, impersonal, with strange and frightening devices, the routine is permeated by procedures that cause pain and discomfort, and by different activities and times from those that one is used to ${ }^{(15)}$.

Using distraction as a tool to improve nutrition is simple, effective and can be adopted by family members of children with difficulty to eat. In this direction, the ludic is recognized as a therapeutic measure that promotes the continuity of children's development and their physical and emotional recovery by making the process of illness less traumatic ${ }^{(10-16)}$.

In this context, playing appears as a care strategy that helps to cope with hospitalization and humanizes child healthcare. Nursing can use playfulness as a tool for the systematization of the playing as a care strategy for hospitalized children, thus configuring comprehensive care based on the assumptions of humanization. By promoting the activity of playing, nursing minimizes the distance between the child, health professional and hospital, rescues the condition of being a child in the hospital environment and takes their uniqueness into consideration ${ }^{(17)}$.

Sleep and rest are essential for children's wellbeing, as physical rest and energy recovery have an important impact on their growth and development, and are fundamental aspects for restoring health ${ }^{(18)}$. In the hospital environment, family caregivers seek to meet children's biological needs and are responsible for their care. In the context of culture and the value system, each family develops its own patterns related to sleep and is concerned when it changes ${ }^{(17)}$.
The hospital is characterized by procedures and exams, which gives the impression that the routine of professionals is more important, and children's sleep can be interrupted at any time. Nursing should plan interventions within this context, seek to change the factors causing intense noise and lighting at night and to reduce interruptions that disturb patients' sleep. Strategies such as planning care actions, adjusting the environment at night and care with noise generation can improve sleep and favor the recovery of patients ${ }^{(19)}$.

The family seeks to be present at the hospital. Depending on the experience of hospitalization, it can be a greater or lesser reason of trauma for the child. The family presence by children's side in the hospital helps to reduce this trauma, has the meaning of safety, care, trust, love and protection, and promotes their adaptation to the hospital environment and treatment ${ }^{(20)}$.

Family members closely monitor children in the hospital, share their care, experience their illness, allow the understanding of hospitalization and offer support and comfort. For the child, family are a reference of support and protection, as their care in the hospital has the affective component needed in this moment. Family members often have little knowledge about their children's disease and seek to learn about care provision in order to ensure, care and offer adequate support, and make efforts in the roles of protection and provision of comfort to the child in the hospital ${ }^{(21)}$. Nurses must be able to plan and develop an appropriate educational process to meet the real needs of children and their family by mediating scientific knowledge and the cultural family care provided to children in the hospital.

Culture has a direct influence on human behavior. When communicating with the patient, nurses must understand their worldview, reflect on the culture, values, beliefs, experiences and meanings that families attribute to the moments lived throughout children's hospitalization ${ }^{(7)}$.

The family ensures that the child receives the prescribed medication properly. Venipuncture is one of the painful procedures that is often performed several times in the same day. For the child, this procedure equals aggression and is commonly accompanied by pain and fear that translate into crying and anxiety ${ }^{(22)}$.

A study was aimed at describing coping strategies for children with cancer dealing with hospitalization, and found that the behavior of taking medications contributes directly to the cure and return to the family environment ${ }^{(23)}$. The act of caring involves respect for the lifestyle of each individual, according to his/her beliefs, values, customs and culture. It is essential that children and their families receive guidance about the treatment and the necessary attention to minimize the trauma of hospitalization ${ }^{(4)}$.

The exercise of religious belief is a manifestation of cultural family care in the hospital. For many people, religion represents a sacred truth of healing based on faith. Religious faith has the power to heal, calm, improve and solve health problems. The relationship between religiosity, health and healing processes is an attempt to understand how individuals experience the disease, suffering, pain and healing practices ${ }^{(24)}$.

As culture significantly influences many aspects of people's lives, including religion, and has important implications for health and healthcare, the biomedical model of healthcare is unable to deal with the complexity of health problems. Thus, the union of 
faith with the treatment of diseases occurs in the search for the improvement of health status ${ }^{(24-25)}$.

The respect for the belief of patients and their families is at health professionals' discretion, as many family members create a barrier in the face of an illness. In this situation, offering a rational perspective to the patient or family caregiver can change the perception of the disease or the therapeutic scheme. By valuing the religious aspects of care, the biological path is not being denied, but considered within a broader analysis dedicated to the historical and cultural dimension of the phenomenon ${ }^{(24)}$.

\section{Study limitations}

The limitation of the study was its development in a single context. Future research must be performed in other contexts related to cultural family care and to how nursing has been contemplating transculturality in its professional practice, which may contribute to new advances on this theme.

\section{Contributions to the field of nursing and public health}

The study contributes with important information on the way the family take care of the child in the hospital setting, based on their cultural references. It is important that nurses consider this aspect in their care practice.

Cultural care is a process that adds knowledge and can be considered a new paradigm for the performance of nursing care. Therefore, the study contributes to public health by providing mutual growth, the construction of new knowledge, an affective, reflective, human and empathic relationship between nurse/ child/family at the time of hospitalization.

\section{FINAL CONSIDERATIONS}

The beliefs, values and practices of families in the care of hospitalized children depend on their cultural references and are manifested through the care with food, clothing and hygiene, maintenance of sleep and rest, of being present, of care with medication and the exercise of religious belief. The family take care of the child in the hospital environment based on their cultural references, and it is important that nurses consider this aspect in their care practice. Cultural care is a process that adds knowledge and can be considered a new paradigm for the performance of nursing care; it provides mutual growth, the construction of new knowledge and an affective, reflective, human and empathic relationship between nurse/child/family.

\section{REFERENCES}

1. Xavier DM, Gomes GC, Santos SSC, Lunardi VL, Pintanel AC, Erdmann AL. [The family in the Pediatric Unit: living with rules and hospital routines]. Rev Bras Enferm. 2014;67(2):181-6. doi: 10.5935/0034-7167.20140023 Portuguese.

2. Cabral PFA, Oliveira BE, Anders JC, Souza AIJ, Rocha PK. Perception of the child and adolescent in relation to being dependent on technology: fundamental aspects for nursing care. Texto Contexto Enferm. 2013;22(2):343-51. doi: 10.1590/S0104-07072013000200010

3. Silva JL, Santos EGO, Rocha CCT, Valença CN, Bay Júnior OG. Organization of Nursing work regarding the integration of family care for hospitalized children. Rev Rene. 2015;16(2):226-32. doi: 10.15253/2175-6783.2015000200012

4. Vasli P, Salsali M. Parents' participation in taking care of hospitalized children: A concept analysis with hybrid model. Iran J Nur Midwifery Res [Internet]. 2014 [cited 2019 Jan 23];19(2):139-44. Available from: https://www.ncbi.nlm.nih.gov/pubmed/24834082

5. Leininger, M. Etnography and ethnonursing: models and modes of qualitative data analysis. Orlando: Grune e Stratton, 1985.

6. Leininger M, Farland MR. Culture care diversity and universality: a worldwide nursing theory. 2. ed. Toronto: Jonesand Bartle, 2006.

7. Leininger, M. Culture diversity and universality: a theory of nursing. New York: National League for Nursing Press, 1991.

8. Khajeh M, Dehghan Nayeri N, Bahramnezhad F, Sadat Hoseini AS. Family centered care of hospitalized children: a hybrid concept analysis in Iran. Health Promot Perspect. 2017;7(4):210-5. doi: 10.15171/hpp.2017.37

9. Coyne I. Families and health-care professionals' perspectives and expectations of family-centered care: Hidden expectations and unclear roles. Health Expect. 2015;18(5):796-808. doi: 10.1111/hex.12104

10. Sueiro IM, Silva LF, Goes FGB, Moraes JRMM. [Nursing in Response to the Challenges Faced by the Family in Feeding Children in Chemotherapy]. Aquichan. 2015;15(4):508-20. doi: http://dx.doi.org/10.5294/aqui.2015.15.4.6 Portuguese.

11. Rodrigues CN, Rosa COB, Ribeiro SMR, Santos CA, Firmino HH. [Nutritional profile and factors associaed with low body weight and reduction of food intake in hospitalized children]. Mundo Saúde. 2016;40(1):61-72. doi: http://dx.doi.org/10.15343/0104-7809.201640016172 Portuguese.

12. Gomes GC, Leite FLLM, Souza NZ, Xavier DM, Cunha JC, Pasini D. [Social support demands of families with children with cerebral palsy]. Rev Eletr Enferm. 2014;16(2):434-42. doi: http://dx.doi.org/10.5216/ree.v16i2.21112 Portuguese.

13. Ponte KMA, Gomes MCF, Ponte HMS, Farias MS. [Nursing cares that Provide Comfort to the Hospitalized Child: Responsible's View]. Cient Ciênc Biol Saúde [Internet]. 2015 [cited 2019 Jan 23];17(3):165-8. Available from: http://pgsskroton.com.br/seer/index.php/JHealthSci/ article/viewFile/3063/2861 Portuguese.

14. Azevêdo AVS, Lançoni Jr AC, Crepaldi MA. Nursing team, family and hospitalized child interaction: an integrative review. Ciênc Saúde Coletiva [Internet]. 2017 [cited 2019 Jan 23];22(11):3653-66. Available from: https://www.scielosp.org/pdf/csc/2017.v22n11/3653-3666/en 
15. Gomes GC, Mota MS, Moreira MAJ, Jung BC, Xavier DM, Silva CD. [(Des) Preparation of family member for the care of children with chronic illness]. Rev Enferm UFPI. 2017;6(1):47-53. doi: 10.26694/reufpi.v6i1.5737 Portuguese.

16. Juzwiak CR. Era uma vez... um olhar sobre o uso dos contos de fada como ferramenta de educação alimentar e nutricional. Interface. 2013;17(45):473-84. doi: 10.1590/S1414-32832013000200019

17. Martins AKL, Silva RG, Fernandes CM, Souza AMA, Vieira NFC. Effects of clown therapy in the child's hospitalization process. Rev Pesqui: Cuid Fundam. 2016;8(1):3968-78. doi: 10.9789/2175-5361.rpcfo.v8.4206

18. Silva BEM, Simões PAD, Macedo MCSA, Duarte JC, Silva DM. [Parents' perception of the sleep habits and quality of preschool-aged children]. Rev Enferm Ref. 2018;serIV(17):63-72. doi: 10.12707/RIV17103 Portuguese.

19. Salzmann-Erikson M, Lagerqvist $L$, Pousette $S$. Keep calm and have a good night: nurses' strategies to promote inpatients' sleep in the hospital environment. Scand J Caring Sci. 2015;30(2):356-64. doi: 10.1111/scs.12255

20. Sumanović-Glamuzina D, Sesar I, Krišto B, Ostojić L. Child and family-centered care in the treatment of children - knowledge, attitudes, practice. Psychiatr Danub [Internet]. 2013 [cited 2019 Jan 23];25(1):37-40. Available from: https://www.ncbi.nlm.nih.gov/pubmed/23806965.

21. Romaniuk D, O'mara L, Akhtar-Danesh N. Are parents doing what they want to do? congruency between parents' actual and desired participation in the care of their hospitalized child. Issues Compr Pediatr Nurs. 2014;37(2):103-21. doi: 10.3109/01460862.2014.880532

22. Emidio S. The viewpoint of hospitalized children with regards to oncological treatment. Rev Pesqui: Cuid Fundam. 2018;10(4):1141-9. doi: 10.9789/2175-5361.2018.v10i4.1141-1149

23. Lopes GC. A compreensão da doença, do tratamento quimioterápico e as formas de enfrentamento de crianças com câncer. [Dissertação] [Internet]. Botucatu: Universidade Estadual Paulista Julio de Mesquita Filho, Faculdade Medicina; 2016 [cited 2019 Oct 11]. Available from: http://hdl.handle.net/11449/144998

24. Santos LM, Valois HR, Santos SSBS, Carvalho ESS, Santana RCB, Sampaio SS. [Applicability of theoretical model to families of children with chronic disease in intensive care]. Rev Bras Enferm. 2014;67(2):187-94. doi: 10.5935/0034-7167.20140024 Portuguese.

25. Robertti Jr JP, Benetti IC, Zanella M. Cultura e processos de saúde e doença. Braz J Mental Health. 2016;8(18):xx. Available from: http://stat. necat.incubadora.ufsc.br/index.php/cbsm/article/view/4423/4738 Portuguese. 